\title{
SISTEM PENDUKUNG KEPUTUSAN PENERIMA BEASISWA BERBASIS WEBSITE STUDI KASUS PEMERINTAH DAERAH KABUPATEN LUWU UTARA
}

\author{
Hasrul ${ }^{1}$, Muhammad Yusuf Mappeasse ${ }^{2}$, Sarmawati ${ }^{3}$ \\ ${ }^{1}$ Pendidikan Teknik Elektro, Universitas Negeri Makassar \\ hasrulbakri@unm.ac.id \\ ${ }^{2}$ Pendidikan Teknik Elektro, Universitas Negeri Makassar \\ muh.yusuf.mappeasse@unm.ac.id \\ ${ }^{3}$ Pendidikan Teknik Elektro, Universitas Negeri Makassar \\ Sarmawati147@gmail.com
}

\begin{abstract}
ABSTRAK
Jenis penelitian yang digunakan adalah R \& D (Research and Development). Penelitian ini bertujuan untuk mengembangkan dan mengetahui kelayakan sistem pendukung keputusan penerima beasiswa Pemerintah Daerah Kabupaten Luwu Utara berbasis website. Data dikumpulkan menggunakan wawancara, dokumentasi, dan kuesioner. Teknik analisis data yang digunakan adalah analisis deskriptif. Sedangkan untuk pengujian kualitas perangkat lunak berdasarkan pengujian standar ISO 25010 menggunakan enam karakteristik yaitu functionality, performance efficiency, portability, usability, reliability dan compatibility. Instrumen pengujan functionality menggunakan metode test case, pengujian performance efficiency menggunakan test tools dari WebSitePulse, pengujian Reliability menggunakan software web server stress tool, pengujian portability menggunakan software browserstack, pengujian usability menggunakan kuesioner yang berisi 13 pernyataan, sedangkan pengujian compatibility menggunakan compatibility testing tools yaitu IE NetRenderer. Hasil dari pengujian functionality berada pada kategori receptable. Hasil pengujian performance efficiency dinyatakan status pengujian baik. Hasil pengujian reliability sistem dapat berjalan dengan baik dengan persentase sukses per URL 100\%. Hasil pengujian portability menunjukkan bahwa sistem ini mendukung desktop dan OS mobile. Hasil pengujian usability menunjukkan kategori baik. Hasil pengujian compatibility sistem dapat diakses dengan baik dan hasil perhitungan menggunakan metode SAW (Simple Additive Weighting) dengan perhitungan manual sesuai sehingga sistem dapat berjalan dengan baik sesuai dengan rancangan.
\end{abstract}

Kata Kunci: Pengambilan Keputusan, Beasiswa, Metode SAW, ISO 25010.

\section{SCHOLARSHIP DECISION SUPPORT SYSTEM BASED ON CASE STUDY WEBSITE REGIONAL GOVERNMENT LUWU UTARA REGENCY}

\begin{abstract}
The type of research used is $R \& D$ (Research and Development). This study aims to develop and determine the feasibility of a website-based decision support system for local government scholarship recipients of North Luwu Regency. Data were collected using interviews, documentation, and questionnaires. The data analysis technique used is descriptive analysis. Meanwhile, for software quality testing based on ISO 25010 standard testing, six characteristics are used, namely functionality, performance efficiency, portability, usability, reliability and compatibility. The functionality testing instrument uses the test case method, performance efficiency testing using test tools from WebSitePulse, reliability testing using web server stress tool software, portability testing using browserstack software, usability testing using a questionnaire containing 13 statements, while compatibility testing using compatibility testing tools, namely IE NetRenderer. The results of the functionality test are in the acceptable category. The results of the performance efficiency test stated that the test status was good. The results of the system reliability test can run well with a $100 \%$ success percentage per URL. The portability test results show that this system supports desktop and mobile OS. The usability test results show a good category. The results of the system compatibility test can be accessed properly and the results of calculations using the SAW (Simple Additive Weighting) method with manual calculations are appropriate so that the system can run properly according to the design.
\end{abstract}

Keyword: Decision Making, Scholarship, SAW Method, ISO 25010. 


\section{PENDAHULUAN}

Pengambilan keputusan pada dasarnya adalah aktivitas manusia yang bertugas untuk memberikan pertimbangan keputusan pada suatu permasalahan [1]. Pengambilan keputusan merupakan hal yang sangat penting dalam berbagai organisasi baik perusahan maupun dalam dunia pendidikan. Olehnya itu keputusan yang diambil sedapat mungkin didukung oleh data.

Pada dunia pendidikan pengambilan keputusan biasa digunakan dalam penentuan penerima beasiswa dan pendidikan gratis. Salah satu hal yang data dimanfaatkan dalam hal pengambilan keputusan adalah dengan menggunakan sebuah sistem yaitu Sistem Pendukung Keputusan (SPK) atau Computer Based Decision Support System (DSS).

Menurut [2] dalam rangka meningkatkan proses dan kualitas dalam pengambilan keputusan dapat menggunakan sistem pendukung keputusan atau decision support system (DSS). DSS dapat mengintegrasikan data dan pengetahuan untuk meningkatkan efektivitas dan efisiensi dalam proses pengambilan keputusan. Sistem Pendukung Keputusan atau Decision Support System (DSS) dapat memberdayakan sumber daya individu secara cermat dengan bantuan kemampuan komputer dalam meningkatkan kualitas keputusan [3].

Pengembangan sistem pendukung keputusan penerimaan beasiswa Pemerintah Daerah Kabupaten Luwu Utara ini didasarkan pada pentingnya beasiswa untuk kelancaran pendidikan anak-anak indonesia. Kenyataan bahwa pengumpulan berkas untuk mendapatkan beasiswa dari Pemerintah Kabupaten Luwu utara masih menggunakan cara konvensional. Pengumpulan berkas dilakukan dalam bentuk hardcopy dan disetor langsung ke Badan Pengelola Keuangan dan Aset Negara Kabupaten Luwu Utara. Tentunya hal ini tidak efisien sebab sangat tergantung pada sumber daya manusia dan membutuhkan waktu serta tenaga untuk mengumpulnya langsung ke tempat penyetoran berkas. Terlebih lagi banyak dari masyarakat Luwu Utara yang melanjutkan pendidikannya di luar dari Kabupaten Luwu Utara. Sehingga hal ini membutuhkan biaya yang cukup banyak untuk melakukan penyetoran berkas Berdasarkan hasil wawancara dengan salah seorang penerima beasiswa ini juga mengeluhkan mengenai antrian yang cukup panjang ketika hendak menyetor berkas.
Hasil wawancara dengan Kepala Badan BPKAD Luwu Utara yang menyatakan bahwa proses seleksi penerima beasiswa ditentukan berdasarkan urutan pendaftar tercepat dikarenakan tidak memungkinkan dilakukannya pemeriksaan secara manual, dan hal tersebut sangat tidak efektif. Berdasarkan permasalahan tersebut, dapat dinilai bahwa perlunya pemanfaatan teknologi untuk menyelesaikan permasalahan tersebut. Data- data dan berkas yang seharusnya disetor langsung dalam bentuk hardcopy dikonversikan ke dalam suatu sistem berbasis website yang memungkinkan mahasiswa mengirimkan data dan berkasnya secara mudah dalam bentuk digital.

\section{METODE PENELITIAN}

Penelitian ini adalah penelitian Research and Development ( $\mathrm{R} \& \mathrm{D})$ atau penelitian dan pengembangan. Penelitian research and development ( $R \& D)$ adalah metode penelitian dan pengembangan yang digunakan untuk menghasilkan produk tertentu dan menguji keefektifan produk tersebut [4].

\section{A. Teknik Pengumpulan Data}

Pengumpulan data merupakan hal yang sangat penting dalam proses penelitian dengan tujuan mengumpulkan data yang valid sehingga dapat digunakan dalam proses penelitian [5]. Beberapa metode dalam pengumpulan data sebagai berikut

\section{Observasi}

Observasi merupakan kegiatan pengumpulan data dengan melakukan pengamatan langsung dalam proses seleksi penerimaan beasiswa Pemerintah daerah Kabupaten Luwu Utara.

\section{Wawancara}

Pengumpulan data melalui wawancara yaitu dengan melakukan kegiatan tanya jawab kepada panitia seleksi beasiswa untuk mendapatkan informasi mengenai alur dan data dalam proses seleksi

\section{Studi Pustaka}

Studi Pustaka dilakukan dalam rangka memperoleh sumber-sumber literatur baik dari jurnal, buku, dan referensi lain yang mendukung dalam proses penelitian.

\section{B. Pengembangan Sistem}

Proses pengembangan system dapat dilakukan dengan Langkah-langkah berikut:

1. Analisa Sistem

Analisa system dilakukan untuk menganalisis kebutuhan system yang akan dibuat. hal tersebut dapat dilakukan hanya jika data pendukung sudah diperoleh. Data yang dibutuhkan yaitu data pendaftaran, data kriteria penerima beasiswa, data 
bobot penilaian, dan data kuota [6] .

\section{Desain Sistem}

Desain system dilakukan setelah melakukan analysis system. Desain system ini dilakukan untuk merancang system sehingga mudah dalam implementasinya.

3. Implementasi Sistem

Implementasi system merupakan tahapan membuat program Sistem Pendukung Keputusan dengan menggunakan Bahasa pemprograman dan database.

\section{Pengujian Sistem}

Pengujian system dilakukan untuk melihat sejauh mana system bekerja dengan baik terutama kualitas fungsional. Pada pengujian system ini dilakukan beberapa pengujian untuk memastikan semua komponen yang ada pada system dapat berfungsi dengan baik.

\section{HASIL DAN PEMBAHASAN}

\section{A. Hasil Penelitian}

Pada bagian ini akan diuraikan proses pengembangan sistem informasi pengambilan keputusan seleksi penerimaan beasiswa menggunakan metode SAW (Simple Additive Weighting) pada Pemerintah Daerah Kabupaten Luwu Utara yang telah dikembangkan dan hasil pengujian yang telah dilakukan.

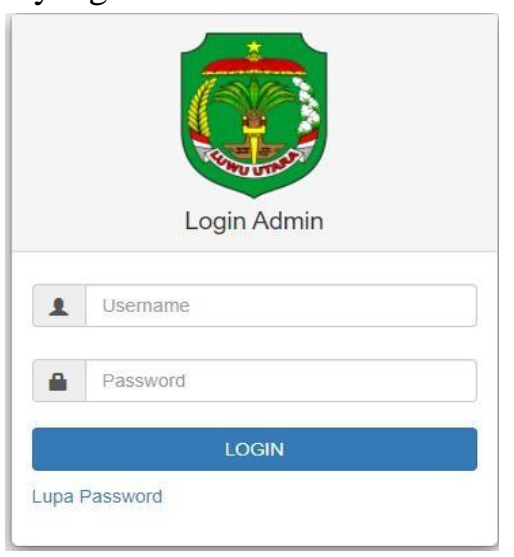

Gambar 1. Halaman Login Admin

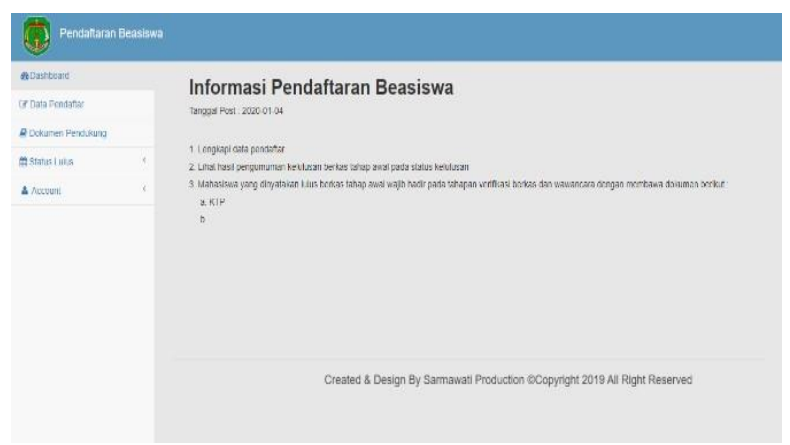

Gambar 2. Halaman Utama User

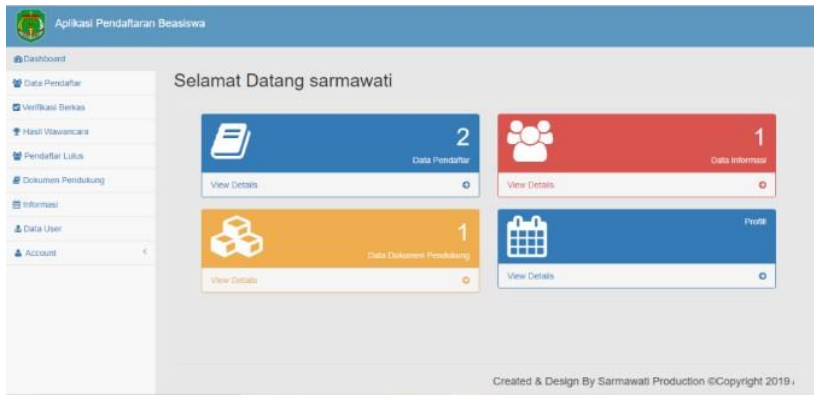

Gambar 3. Halaman Utama Admin

\section{B. Analisis Data}

Pengujian kelayakan Sistem berdasarkan ISO 25010 Pengujian perangkat lunak hanya menggunakan enam karakteristik saja yaitu functional suitability, performance efficiency, usability, compatibility, Reliability, dan portability karena sudah cukup untuk menguji kualitas perangkat lunak.

1. Pengujian Functional Suitability.

Hasil dari uji functional Suitability berupa test case yang divalidasi oleh dosen ahli sebagai validator. Tabel rekapitulasi pengujian functional suitability untuk menentukan nilai testing criteria digunakan persamaan [7].

$$
x=\frac{A}{B} \times 100
$$

$\mathrm{X}=$ Hasil Functional Suitability

A = Jumlah fungsi yang berfungsi dengan baik

$\mathrm{B}=$ Jumlah fungsi yang dievaluasi

TABEL 1. PENILAIAN FUNCTIONAL SUITABILITY

\begin{tabular}{ccccc}
\hline Validator & $\begin{array}{c}\text { Skor yang } \\
\text { diobservasi }\end{array}$ & $\begin{array}{c}\text { Skor yang } \\
\text { diharapkan }\end{array}$ & $\begin{array}{c}\text { Kelayakan } \\
(\boldsymbol{\%})\end{array}$ & Kategori \\
\hline $\begin{array}{c}\text { Validator } \\
1\end{array}$ & 58 & 58 & $100 \%$ & $\begin{array}{c}\text { Sangat } \\
\text { Baik }\end{array}$ \\
$\begin{array}{c}\text { Validator } \\
2\end{array}$ & 58 & 58 & $100 \%$ & $\begin{array}{c}\text { Sangat } \\
\text { Baik }\end{array}$ \\
\hline & Rata-rata & & $\mathbf{1 0 0 \%}$ & $\begin{array}{c}\text { Sangat } \\
\text { Baik }\end{array}$ \\
\hline
\end{tabular}

Karena $\mathrm{A}=58$ dan $\mathrm{B}=58$ maka testing criteria bernilai 100. Hal ini berarti bahwa aspek functional suitability sistem informasi yang dikembangkan berada pada kategori receptable (dapat diterima).

\section{Pengujian Usability}

Berdasarkan perhitungan hasil kuesioner diperoleh rata-rata skor terbanyak 59 dengan tingkat kelayakan $90 \%$ atau sangat baik. Analisis dari pengujian usability menggunakan analisis deskriptif dengan rumus [8]:

$$
\text { Kelayakan }(\%)=\frac{\text { Skor } \text { yang diobservasi }}{\text { Skor yang diharapkan }} \times 100 \%
$$

Pada Tabel 2 diperoleh kesimpulan bahwa 18 orang responden mengatakan Sangat Baik atau 78\% dari jumlah responden, dan 5 orang responden 
mengatakan baik atau $22 \%$ dari jumlah responden, sedangkan untuk kategori cukup, kurang dan sangat kurang sebanyak 0 orang atau $0 \%$.

TABEL 2. PENILAIAN USABILITY

\begin{tabular}{lcc}
\hline Kategori & $\begin{array}{c}\text { Jumlah } \\
\text { Responden }\end{array}$ & Presentase \\
\hline Sangat Baik & 18 & $78 \%$ \\
Baik & 5 & $22 \%$ \\
Cukup Baik & 0 & $0 \%$ \\
Kurang Baik & 0 & $0 \%$ \\
Sangat Tidak Baik & 0 & $0 \%$ \\
\hline Jumlah & $\mathbf{2 3}$ & $\mathbf{1 0 0 \%}$ \\
\hline
\end{tabular}

3. Pengujian Reliability

Pengujian Reliability menggunakan aplikasi Web Server Stress Tools yang digunakan untuk menguji stabilitas dan kemampuan sistem dalam menerima traffic yang tinggi. Tes ini terutama menentukan sistem pada ketahanan dan penanganan error dibawah kondisi beban yang sangat berat. Pada pengujian menggunakan aplikasi ini terdapat tiga pengujian yaitu: click test, time test, dan ramp test.

TABEL 3. PENGUJIAN RELIABILITY

\begin{tabular}{lll}
\hline Jenis Test & $\begin{array}{l}\text { Presentae } \text { error } \\
\text { per URL }\end{array}$ & $\begin{array}{l}\text { Presentase } \\
\text { Sukses per URL }\end{array}$ \\
\hline Click Test & $0 \%$ & $100 \%$ \\
Time & $0 \%$ & $100 \%$ \\
Test & & \\
Ramp Test & $0 \%$ & $100 \%$ \\
\hline Rata- rata & $0 \%$ & $100 \%$ \\
\hline
\end{tabular}

Berdasarkan Tabel 3, diperoleh rata- rata persentase sukses per test sebesar $100 \%$ hal ini berarti bahwa sistem informasi yang dikembangkan memiliki stabilitas yang baik.

\section{Pengujian Metode $S A W$}

Pada penelitian ini, teknik identifikasi masalah yang dihadapi menggunakan metode SAW (Simple Additive Weighting). Konsep dasar metode SAW adalah mencari hasil terbaik dari proses normalisasi sesuai dengan persamaan (rumus) SAW dengan kriteria yang ada pada setiap alternatif untuk ditentukan alternatif terbaik. Persamaan (rumus) untuk melakukan normalisasi tersebut adalah sebagai berikut [9]:

$r_{i j}=$
$\left\{\begin{array}{l}\frac{X_{i j}}{\operatorname{Max} x_{i j}} \text { Jika } j \text { ialah atribut keuntungan (benefit) } \\ \frac{i}{\operatorname{Min} X_{i j}} \\ \frac{i}{X_{i j}}\end{array}\right.$
Keterangan:

$\mathrm{r}_{\mathrm{ij}} \quad=$ nilai rating kinerja ternormalisasi

$\operatorname{Max}_{i}=$ nilai maksimum dari setiap baris dan kolom

$\operatorname{Min}_{\mathrm{i}}=$ nilai minimum dari setiap baris dan kolom

$\mathrm{X}_{\mathrm{ij}} \quad=$ baris dan kolom dari matriks

Keterangan:

$$
V_{i}=\sum_{j=1}^{n} W_{j} r_{i j}
$$

$\mathrm{V}_{\mathrm{i}} \quad=$ hasil akhir untuk setiap alternatif

$\mathrm{W}_{\mathrm{j}} \quad=$ nilai bobot preferensi

$\mathrm{r}_{\mathrm{ij}} \quad=$ nilai rating kinerja ternormalisasi

Metode $S A W$ ini mengharuskan pembuat keputusan menentukan bobot masing-masing kriteria dan dalam penentuan atributnya (benefit atau cost) harus disesuaikan dengan kriteria yang ada.

TABEL 4. HASIL PROSES PERANGKINGAN

\begin{tabular}{|c|c|c|c|c|c|}
\hline \multirow{2}{*}{ Alternatif } & \multicolumn{3}{|c|}{ Atribut (Kriteria) } & \multirow{2}{*}{ Hasil } & \multirow{2}{*}{ Rangking } \\
\hline & C1 & $\mathrm{C2}$ & $\mathrm{C3}$ & & \\
\hline Aeni & 10 & 10 & 7.5 & 9 & 1 \\
\hline Iqbal & 7.5 & 7.5 & 7.5 & 8.5 & 2 \\
\hline Ardiyansyah & 7.5 & 7.5 & 7.5 & 7 & 3 \\
\hline Ayu Ashari & 5 & 10 & 7.5 & 5 & 4 \\
\hline
\end{tabular}

Hasil perhitungan dengan menggunakan sistem maupun menggunakan perhitungan manual sesuai sehingga sistem dapat berjalan dengan baik sesuai dengan rancangan.

\section{SIMPULAN}

1. Pengembangan sistem pendukung keputusan penerima beasiswa Pemerintah daerah Kabupaten Luwu Utara berbasis website dilakukan dengan model pengembangan prototyping yang terdiri atas 6 langkah yaitu pengumpulan kebutuhan, membangun prototyping, evaluasi Prototyping, mengkodekan sistem, menguji sistem dan menggunakan sistem. Sistem dikembangkan dengan menggunakan Bahasa pemrogrmann PHP dan pengelolaan database menggunakan MySQL. Hasil pengembangan menghasilkan sistem pendukung keputusan penerima beasiswa Pemerintah Daerah Kabupaten Luwu Utara yang dikelola secara online yang digunakan dalam pendaftaran dan penyeleksian beasiswa.

2. Hasil pengujian perangkat lunak berdasarkan standar kualitas ISO 25010 diperoleh hasil pengujian aspek functionality berada pada kategori dapat diterima, hasil pengujian aspek performance efficiency berada pada kategori baik, hasil pengujian aspek usability berada pada kategori baik, hasil pengujian aspek Reliability sistem memiliki stabilitas yang baik, hasil pengujian aspek compatibility sistem dapat 
diakses dengan baik dan hasil pengujian aspek portability berada pada kategori sangat baik sedangkan pada pengujian hasil perhitungan menggunakan metode SAW sistem maupun menggunakan perhitungan manual cocok sehingga sistem dapat berjalan dengan baik sesuai dengan rancangan.

\section{DAFTAR PUSTAKA}

[1] N. Komalasari, "Sistem Pendukung Keputusan Kelaikan Terbang (SPK2T)," Jurnal Industri Elektro dan Penerbangan, vol. 4, no. 1, 2014.

[2] J. E. Aronson, T.-P. Liang, and R. V. MacCarthy, Decision support systems and intelligent systems, vol. 4. Pearson PrenticeHall Upper Saddle River, NJ, USA:, 2005.

[3] S. Irfan, "Sistem Pendukung Keputusan (Decision Support System)," Jurusan Teknik Informatika, Fakultas Teknologi Informasi, Institut Sepuluh November, Surabaya, 2002.

[4] S. Haryati, "Research and Development (R\&D) sebagai salah satu model penelitian dalam bidang pendidikan," Majalah Ilmiah Dinamika, vol. 37, no. 1, p. 15, 2012.

[5] M. Muqorobin, A. Apriliyani, and K. Kusrini, "Sistem Pendukung Keputusan Penerimaan Beasiswa dengan Metode SAW," Respati, vol. 14, no. 1, 2019.

[6] R. Taufiq and I. S. Mustofa, "Perancangan Sistem Pendukung Keputusan Kejurusan Menggunakan Metode Simple Additive Weighting (SAW) Di SMA Negri 15 Tangerang," Jurnal TI Atma Luhur, vol. 4, no. 1, pp. 103-114, 2017.

[7] R. D. Dako and W. Ridwan, "Pengujian karakteristik Functional Suitability dan Performance Efficiency tesadaptif. net," Jambura Journal of Electrical and Electronics Engineering, vol. 3, no. 2, pp. 6671, 2021.

[8] D. Vitalocca, E. S. Rahman, and N. M. Abdal, "Pengembangan Aplikasi Kemahasiswaan Jurusan Pendidikan Teknik Elektro (AsikJPTE) Berbasis Cloud Computing," Jurnal Media Elektrik, vol. 18, no. 1, pp. 1-7, 2021.

[9] K. Savitha and C. Chandrasekar, "Trusted network selection using SAW and TOPSIS algorithms for heterogeneous wireless networks," arXiv preprint arXiv:1108.0141, 2011. 